\title{
Physical and psychological welfare of students at higher educational establishments during "soft" fitness and classical aerobics lessons
}

\author{
Evgeniya Shirokova $^{{ }^{*}}$, Vera Makeeva ${ }^{2}$, Galina Yamaletdinova ${ }^{3}$, Marina Shchegoleva ${ }^{1}$ \\ ${ }^{1}$ Kaluga State University named after K. Tsiolkovsky, 248023, Kaluga, Russia \\ ${ }^{2}$ Russian State University of Physical Culture, Sport, Youth and Tourism, 105122, Moscow, Russia, \\ ${ }^{3}$ Liberal Arts University, 620049, Ekaterinburg, Russia
}

\begin{abstract}
The article substantiates the necessity to use "soft" fitness during physical culture lessons with students at higher educational establishments at the initial stages of teaching. During the programs of exercises creation the demands claimed on students at the lessons should fully correspond with their physical abilities and psychological needs, as in this case the connection between physical and psychological components of life quality becomes stronger. The need for physical exercises fulfillment and high level of motor activity support becomes the part of psychological comfort and personality's welfare.
\end{abstract}

\section{Introduction}

Nowadays the category "life quality" is an urgent sphere for different knowledge fields study: philosophy, sociology, economics, psychology, pedagogics and others. A healthy way of life and an optimal physical activity form the base for high quality of life and provide effective and productive functioning of a person at all stages of his life.

20-30 years ago if children had free time they actively played outdoor games. Many children went to the village for holidays, owing to which their motor activity, working capacity and health level were sufficiently high. Nowadays the conditions have changed greatly: hypodynamia, life "digitalisation", computers and gadgets lead to the fact that physical abilities of young people decrease.

The tendencies of modern society development reveal the following problem: with age the lack of motor activity among young people becomes worse and it leads to physical fitness, educational activity effectiveness and health level decrease [1,2].

These factors, together with the changes of society and the conditions of its life demand physical culture lessons modification. First of all, it is necessary to take into account that physical and psychological components of life quality are closely connected with each other: only if physical culture lessons will fully satisfy psychological needs and correspond with physical abilities of young people, it is possible to change motivation for motor activity and the desire to realize physical self-development.

\footnotetext{
Corresponding author: kaktus86@mail.ru
} 
During the exercises selection for the programs it is necessary to take into account that actively developing fitness culture leads to needs change in students concerning "Physical culture and sport" subject: urgent becomes the desire to have qualitative and interesting leisure, positive emotions. There appears the desire to get satisfaction from the lessons in comfortable conditions [3].

Physical education lessons become an important source. It supplies movement. However, a low level of physical conditions doesn't let using high intensity lessons in physical training of young people. In this case motivation can decrease because of physical overloads. Moreover, gender aspect becomes extremely important: women, who regularly go in for low intensive physical load, have higher self- assessment and welfare in comparison with women, who go in for highly-intensive physical exercises. For men inverse effect is typical: they demonstrate higher self-assessment and welfare of higher physical loads [4].

Other authors, summarizing the research works concerning the presented problem, come to the conclusion that the leading motivation is especially important: exercises, directed toward weight decrease, are connected with lower life quality (as there is motivation decrease, dissatisfaction with own body). At the same time, the exercises, which improve mood and health level, condition higher life quality [5].

Thus, not always intensive loads have positive influence on health state and life quality. For highly-intensive activity inclusion it is necessary to have serious motivation and corresponding physical fitness.

During the content of the lessons selection it is necessary to take into account tendencies in the society: nowadays we see the desire of people to have comfort in all spheres of activity, including the sphere of health-improving physical education. In modern fitnessindustry together with popular highly-intensive programs (HIIT, Cross fit, Cycle) become popular low-intensive programs. They are based on eastern health-improving practices. Their other names are the following: Body\&Mind, "clever" fitness, "mental" fitness, "soft" fitness [6].

The main aim of the mentioned programs is in self-development, harmony achievement, health and physical state improvement [7, 8].The programs have health-improving orientation, omit dangerous exercises. They can get injuries, have opportunities for load regulation, owing to which they are available for most part of population. One of relative peculiarities of these programs is control over body during the lessons. Owing to concentration and attention redirection during the exercises fulfillment there appears a vivid psycho-regulating effect. It leads to nervous-psychic tension, the degree of stress decrease, regulatory skills gaining. It corresponds with the concept of perception by Norman Farb [9]. Held by L. Schneider and his colleagues in 2007 research works proved that perception (in this case body feelings) helps to change the regimen of brain work, owing to which psychoregulating effects happen. Realized physical exercises fulfillment gains popularity abroad, there appear new studies and research works [10, 11,12].

Mentioned peculiarities of "soft" fitness programs will be especially useful in terms of high mental loads. Students have them at the initial stages of study at a higher educational establishment. Moreover, awareness of movements fulfillment helps to feel the body better, regulate the load, without any harm to the organism, train with comfort for own body. It will let a person come to the realized need for regular physical activity and physical selfdevelopment.

The main aim of the present research work: to reveal interconnection of psychological and physical aspects of students' life quality during "soft" fitness and classical aerobics lessons.

\section{Materials and Methods}


87 students from Kaluga State University named after K.E. Tsiolkovskiy (Kaluga, Russia) and Humanitarian University (Ekaterinburg, Russia) took part in the research.

The control group (42 people) went in for classical aerobics with shaping elements inclusion.

The experimental group (45 people) trained according to created methodology of "soft" fitness. It included the exercises of low and average intensity. The experimental methodology included modified exercises of a functional training, pilates, stretching, myofascial relaxation and autogenic training. At the same time, an important factor was conjugate use of motor activity means and psycho-regulating effects. Special attention was paid to awareness during the exercises fulfillment.

In order to reveal the interconnection between physical and psychological indices of life quality we used correlation analysis (Pearson correlation coefficient).

As the parameters of physical welfare we chose the following parameters:

- physical education lessons attendance;

- the level of motor activity (fitness-trackers Xiaomi MiBand were used);

- general index of physical readiness (was calculated by means of the average values summing up, received for control normatives fulfillment)

As the parameters of psychological welfare we chose the following parameters:

- adaptive potential of a personality (for its estimation we used multilevel personal questionnaire "Adaptivity" A. G. Maklakov, S. V. Chermyanin);

- the level of psycho-social stress (for its estimation we used L.Reader methodology);

- general level of satisfaction with life (for its estimation we used satisfaction with life scale by E. Diener).

\section{Results and Discussion}

At the beginning of the research we revealed positive interconnections between personal adaptive potential index and satisfaction with life $(R=0,486, p<0,01)$ in the experimental group. At the same time, invert correlation is mentioned with the degree of psycho-social stress demonstration $(-0,568, \mathrm{p}<0,01)$. Weak correlational connections were between adaptive abilities and motor activity $(\mathrm{R}=0,348, \mathrm{p}<0,05)$ and physical readiness $(\mathrm{R}=0,296$, $\mathrm{p}<0,05)$. Moreover, students, who had more distinct degree of psycho-social stress more often attend physical education lessons $(R=0,350, p \leq 0,05)$.

General level of satisfaction with life is connected with the level of motor activity during the day $(\mathrm{R}=0,395, \mathrm{p}<0,01)$. Physical education lessons attendance among the respondents from the experimental group had low-grade invert correlation with physical readiness $\left(\mathrm{R}=-0,296^{*}, \mathrm{p} \leq 0,05\right)$. Moreover, general level of motor activity turned out to be connected with physical readiness $\left(\mathrm{R}=0,333^{*}, \mathrm{p} \leq 0,05\right)$. The results are presented in table 1 .

Table 1. Correlation matrix of physical and psychological welfare indices in the respondents from the experimental group at the beginning of the experiment

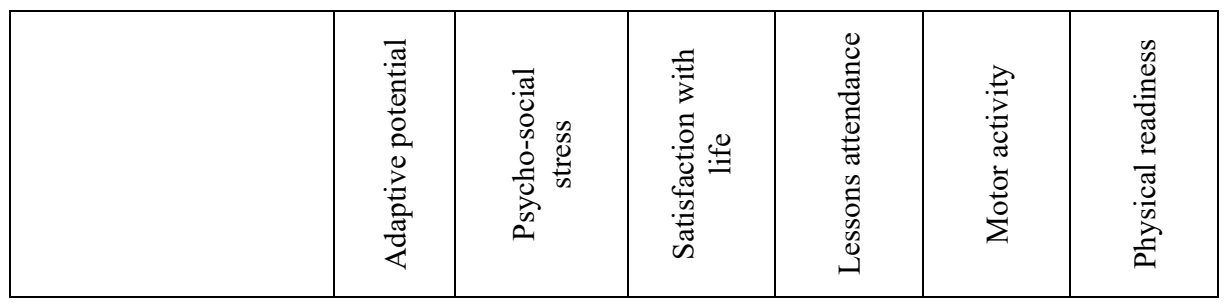




\begin{tabular}{|c|c|c|c|c|c|c|}
\hline Adaptive potential & 1 & $\begin{array}{c}-0,568^{* *} \\
0,000\end{array}$ & $\begin{array}{c}0,486^{* *} \\
0,001\end{array}$ & $\begin{array}{c}0,208 \\
0,171\end{array}$ & $\begin{array}{c}0,348^{*} \\
0,024\end{array}$ & $\begin{array}{c}0,296^{*} \\
0,049\end{array}$ \\
\hline Psycho-social stress & & 1 & $\begin{array}{c}-0,213 \\
0,089\end{array}$ & $\begin{array}{c}0,350^{*} \\
0,018\end{array}$ & $\begin{array}{c}-0,106 \\
0,502\end{array}$ & $\begin{array}{c}-0,17 \\
0,911\end{array}$ \\
\hline Satisfaction with life & & & 1 & $\begin{array}{c}-0,120 \\
0,430\end{array}$ & $\begin{array}{c}0,395^{* *} \\
0,010\end{array}$ & $\begin{array}{c}0,194 \\
0,202\end{array}$ \\
\hline Lessons attendance & & & & 1 & $\begin{array}{c}-0,164 \\
0,300\end{array}$ & $\begin{array}{c}-0,296^{*} \\
0,048\end{array}$ \\
\hline Motor activity & & & & & & $0,333^{*}$ \\
& & & & & & \\
\hline Physical readiness & & & & & & \\
\hline
\end{tabular}

Notes: 1 line - Spearman correlation coefficient value, 2 line - significance level; * - $\mathrm{p} \leq 0,05 ; * *$ $\mathrm{p} \leq 0,01$

Similar correlation connections were revealed at the initial stage of the research in the control group. Personal adaptive potential is connected with satisfaction with life $(\mathrm{R}=0,323$, $\mathrm{p}<0,05)$, invert interrelation was stated by psycho-social stress indices $(-0,568, \mathrm{p} \leq 0,01)$.

Weak interrelations were stated between persional adaptive potential and physical readiness $\left(\mathrm{R}=0,316^{*}, \mathrm{p} \leq 0,05\right)$. Students, who had high degree of psycho-social stress more actively attended physical culture lessons $(\mathrm{R}=0,462, \mathrm{p} \leq 0,01)$. Moreover, there was weak correlation between general level of motor activity and satisfaction with life $(R=0,320$, $\mathrm{p} \leq 0,05)$, and physical readiness $(\mathrm{R}=0,357, \mathrm{p} \leq 0,05)$. The results are presented in table 2 .

Table 2. Correlation matrix of physical and psychological welfare indices in the respondents from the control group at the beginning of the experiment

\begin{tabular}{|c|c|c|c|c|c|c|}
\hline & 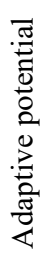 & 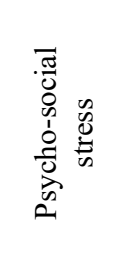 & 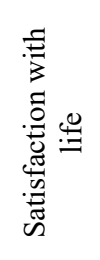 & 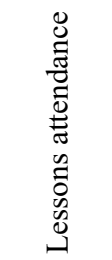 & 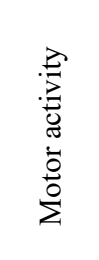 & 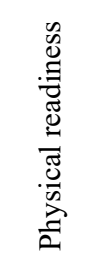 \\
\hline Adaptive potential & 1 & $\begin{array}{c}-0,549 * * \\
0,000\end{array}$ & $\begin{array}{c}0,323^{*} \\
0,037\end{array}$ & $\begin{array}{c}-0,378^{*} \\
0,013\end{array}$ & $\begin{array}{l}0,108 \\
0,498\end{array}$ & $\begin{array}{c}0,316^{*} \\
0,041\end{array}$ \\
\hline Psycho-social stress & & 1 & $\begin{array}{l}-0,135 \\
0,395\end{array}$ & $\begin{array}{c}0,462 * * \\
0,02\end{array}$ & $\begin{array}{l}-0,93 \\
0,559\end{array}$ & $\begin{array}{c}-0,258 \\
0,99\end{array}$ \\
\hline Satisfaction with life & & & 1 & $\begin{array}{c}-0,274 \\
0,79\end{array}$ & $\begin{array}{c}0,320^{*} \\
0,039\end{array}$ & $\begin{array}{l}0,185 \\
0,241\end{array}$ \\
\hline Lessons attendance & & & & 1 & $\begin{array}{l}0,149 \\
0,347\end{array}$ & $\begin{array}{l}-0,66 \\
0,676\end{array}$ \\
\hline Motor activity & & & & & 1 & $\begin{array}{c}0,357 * \\
0,020\end{array}$ \\
\hline
\end{tabular}




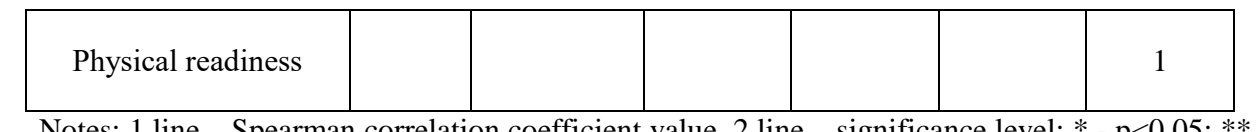
$\mathrm{p}<0,01$

At the final stage of the research work interconnection between adaptive potential and the degree of psycho-social stress $(\mathrm{R}=-0,418, \mathrm{p}<0,01)$ decreases in the experimental group, the connection with satisfaction with life increases $(R=0,512, p<0,01)$. Moreover, the connection of adaptive potential with physical welfare indices becomes stronger: with the level of moor activity $(R=0,354, p \leq 0,05)$ and physical readiness $(R=0,488, p \leq 0,01)$.

There appears invert correlation between psycho-social stress index and satisfaction with life $(\mathrm{R}=-0,303, \mathrm{p}<0,05)$, with the degree of stress increases physical culture lessons attendance $(\mathrm{R}=0,463, \mathrm{p} \leq 0,01)$ (at the end of the experiment correlation increases).

Moreover, the interconnection between general satisfaction with life and physical welfare indices increases: motor activity $(\mathrm{R}=0,432, \mathrm{p} \leq 0,01)$ and physical readiness $(\mathrm{R}=0,342, \mathrm{p} \leq 0,05)$.

There is weak correlation connection between moor activity and physical readiness $(\mathrm{R}=0,308, \mathrm{p} \leq 0,05)$. The results are presented in table 3 .

Table 3. Correlation matrix of physical and psychological welfare indices in the respondents from the experimental group after the experiment

\begin{tabular}{|c|c|c|c|c|c|c|}
\hline & 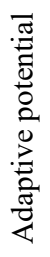 & 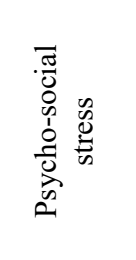 & 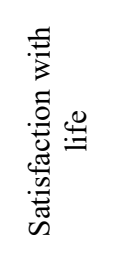 & 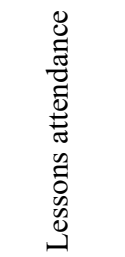 & 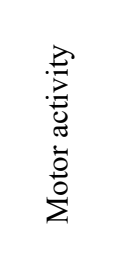 & 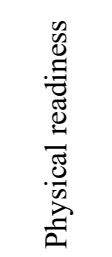 \\
\hline Adaptive potential & 1 & $\begin{array}{c}-0,418 * * \\
0,004\end{array}$ & $\begin{array}{c}0,512 * * \\
0,000\end{array}$ & $\begin{array}{l}0,104 \\
0,503\end{array}$ & $\begin{array}{c}0,354^{*} \\
0,017\end{array}$ & $\begin{array}{c}0,482 * * \\
0,001\end{array}$ \\
\hline Psycho-social stress & & 1 & $\begin{array}{c}-0,303^{*} \\
0,043\end{array}$ & $\begin{array}{c}0,463 * * \\
0,002\end{array}$ & $\begin{array}{c}-0,050 \\
0,742\end{array}$ & $\begin{array}{l}0,125 \\
0,870\end{array}$ \\
\hline Satisfaction with life & & & 1 & $\begin{array}{c}-0,057 \\
0,715\end{array}$ & $\begin{array}{c}0,432 * * \\
0,003\end{array}$ & $\begin{array}{c}0,342^{*} \\
0,047\end{array}$ \\
\hline Lessons attendance & & & & 1 & $\begin{array}{c}-0,204 \\
0,184\end{array}$ & $\begin{array}{c}-0,105 \\
0,497\end{array}$ \\
\hline Motor activity & & & & & 1 & $\begin{array}{c}0,308^{*} \\
0,040\end{array}$ \\
\hline Physical readiness & & & & & & 1 \\
\hline
\end{tabular}

Notes: 1 line - Spearman correlation coefficient value, 2 line - significance level; * - $p<0,05$; ** $\mathrm{p}<0,01$

In the control group adaptive potential indices preserve direct interconnection with satisfaction with life $(\mathrm{R}=0,432, \mathrm{p}<0,01)$ and indirect interconnection with the degree of 
stress $(\mathrm{R}=-0,432, \mathrm{p} \leq 0,01)$. There is no correlation between adaptive potential and physical readiness.

The interconnection between satisfaction with life and the level of motor activity, between motor activity and physical readiness also disappears. The results are presented in table 4.

Table 4. Correlation matrix of physical and psychological welfare indices among the respondents from the control group after the experiment

\begin{tabular}{|c|c|c|c|c|c|c|}
\hline & 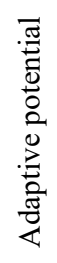 & 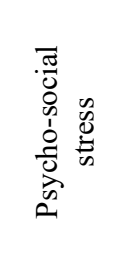 & 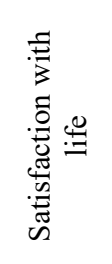 & 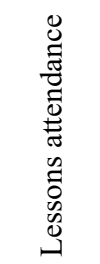 & 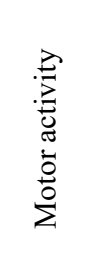 & 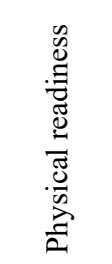 \\
\hline Adaptive potential & 1 & $\begin{array}{c}-0,432 * * \\
0,004\end{array}$ & $\begin{array}{c}0,468 * * \\
0,002\end{array}$ & $\begin{array}{c}-0,086 \\
0,590\end{array}$ & $\begin{array}{l}-0,13 \\
0,935\end{array}$ & $\begin{array}{l}0,274 \\
0,080\end{array}$ \\
\hline Psycho-social stress & & 1 & $\begin{array}{l}-0,236 \\
0,133\end{array}$ & $\begin{array}{c}0,351^{*} \\
0,023\end{array}$ & $\begin{array}{l}0,104 \\
0,510\end{array}$ & $\begin{array}{c}-0,374 * \\
0,015\end{array}$ \\
\hline Satisfaction with life & & & 1 & $\begin{array}{l}0,311 \\
0,045\end{array}$ & $\begin{array}{l}0,085 \\
0,591\end{array}$ & $\begin{array}{l}-0,34 \\
0,839\end{array}$ \\
\hline Lessons attendance & & & & 1 & $\begin{array}{l}0,031 \\
0,845\end{array}$ & $\begin{array}{c}-0,283 \\
0,070\end{array}$ \\
\hline Motor activity & & & & & 1 & $\begin{array}{l}0,009 \\
0,953\end{array}$ \\
\hline Physical readiness & & & & & & 1 \\
\hline
\end{tabular}

Notes: 1 line - Spearman correlation coefficient value, 2 line - significance level; * - p<0,05; ** $\mathrm{p}<0,01$

\section{Conclusions}

Thus, "soft" fitness methodology has a positive influence on interconnections between physical and psychological components of life quality in the experimental group. As a result of it during the final part of the experiment we had the following results:

- the connection between adaptive potential and satisfaction with life increases. The respondents, who have higher adaptive potential, have higher level of motor activity and physical readiness;

-interconnection between subjective satisfaction with life and the level of motor activity increases, there appears connection between subjective satisfaction with life and physical readiness.

Mentioned above factors can prove changes of motivation for physical activity and its role in supporting psychological comfort and personality's welfare.

In the control group physical and psychological welfare indices have less distinctive character and at the end of the experimental research some correlations disappear:

-in case of interconnection preservation between adaptive potential and satisfaction with life the connection between adaptive potential and physical readiness disappears; 
- correlation between satisfaction with life and the level of motor activity disappears.

The revealed peculiarities can show the role of physical culture and motor activity decrease in supporting psychological welfare of respondents from the control group.

Thus, the received results show interconnection strengthening between physical and psychological components of life quality, as a result of "soft" fitness methodology use at physical culture lessons with students from higher educational establishments.

\section{References}

1. E. R. Saleev, Fundamental research works, 12 (3), 529-533 (2014)

2. E.I. Suetina, A. A. Opletin, Physical culture, sport, tourism: scientific-methodical support (Perm State Humanitarian, Perm, 2016)

3. M. K. Lustyk, L. Widman, A.E. Paschane, K.C. Olson, Behavioral Medicine, 30, 124-131 (2004)

4. B. B. Craft, H. A. Carrol, M. Kathleen, B. Lystik, International journal of liberal arts and social science, 2, 65-76 (2014)

5. O.A. Ivanenko, Characteristics of Mind and Body fitness orientation: methodical manual (Ural State University of Physical Culture, Chelyabinsk, 2008).

6. K. Endelman, Club Solutions, January, 12-14 (2005)

7. J. C. Ives, II Physician and Sports medicine, 28, 67-81 (2000).

8. N. Farb, Z. V. Segal, H. Mayberg, J. Bean, D. McKeon, Z. Fatima, A. K. Anderson Soc Cogn Affect Neurosci, 2 (4), 313-322 (2007).

9. J. Schneider, P. Malinowski, P. M. Watson, P. Lattimore, Obesity Reviews 20(3), 448-463 (2018)

10. M. A. Henning, T. J. Park, F. Moir, C. Krägeloh, C. Mysko, J. Hobson, C. S. Webster, OBM Integrative and Complementary Medicine, 3(4) (2018)

11. I.A. Mingalisheva, The Russian Journal of Physical Education and Sport, 13(3), 49-57 (2018)

12. A.S. Kuznetsov, Z.M. Kuznetsova, Russian Journal of Physical Education and Sport, 14(4), 5-7 (2019) 